\title{
Some aspects of problematic alcohol use in Albania
}

\author{
Esmeralda Thoma(Hoxha $)^{1 *}$ and Sonila Bitri ${ }^{2}$ \\ ${ }^{1}$ Clinical toxicologist and addictologist; Lecturer at Faculty of Technical Medical Sciences; Medical University of Tirana \\ ${ }^{2}$ Medical doctor; clinical toxicologist and addictologist and check-up director at American Hospital of Tirana/Albania
}

\begin{abstract}
Introduction: Alcohol use has become really common among males in Albania. Until the late `90 -early `00, alcohol use was almost a male phenomenon. Lately, it is becoming even a female phenomenon. Aim: The aim of this study is to highlight some socio-economic aspects of alcohol abuse in Albania.

Material and method: This is a retrospective study, which included 328 patients, hospitalized at two centers for treatment of alcohol use disorders at UHC "Mother Teresa”. The diagnosis was: Alcohol abuse.

Results: $100 \%$ of the patients were male, due to the fact that alcohol abuse is mainly a male problem. It is very hard for female to accept the problem and therefore ask treatment, due to the greater stigma. The mean age of the patients was $42.9 \pm 10.8$ years old (22-81 years old). $33.5 \%$ were among $31-40$ years old. The category of the unemployed, married, disabled and patients with lower education level consume more alcohol. $79.3 \%$ of all patients of the study used to drink strong alcoholic beverages like "raki”.
\end{abstract}

Conclusions: There are many aspects of socio-economic life of alcohol abuse that differ from those of other countries. If we could highlight these aspects just in time, we can intervene to reduce abusive alcohol consumption.

\section{Introduction}

\section{Alcohol is a psychoactive substance that has dependence producing properties}

The use of alcoholic beverages dates too early. As far as we know the first alcoholic drink was used at least in the year $6000 \mathrm{BC}$ [1]. The use of alcohol is already a phenomenon of many societies. It is estimated that the total number of the population classified as alcohol consumers in the world goes up to 2 billion, while 76.3 million people develop alcohol use disorder [2,3].

Alcohol abuse is a psychiatric diagnosis that describes the chronic use of alcohol, despite adverse effects [4]. Alcoholism and alcohol abuse is the result of the combination of many factors, including genetics, occupational and social environment, mental health and emotional state of the person.

Biological or psychological reasons that leads a person from undercontrolled way of drinking to problematic use/abuse, to alcohol Alcohol is a psychoactive substance that has dependence producing properties.

The use of alcoholic beverages dates too early. As far as we know the first alcoholic drink was used at least in the year $6000 \mathrm{BC}$ [1]. The use of alcohol is already a phenomenon of many societies. It is estimated that the total number of the population classified as alcohol consumers in the world goes up to 2 billion, while 76.3 million people develop alcohol use disorder $[2,3]$.

Alcohol abuse is a psychiatric diagnosis that describes the chronic use of alcohol, despite adverse effects [4] Alcoholism and alcohol abuse is the result of the combination of many factors, including genetics, occupational dependence/ alcoholism include inheritance, candidate genes, alcohol metabolism regulatory system and the influence of alcohol on different neurotransmitter systems.

\section{Material and method}

This is a retrospective cohort study that was conducted during the years 2012- 2013 in two clinics which treat alcohol use disorders: Center of Addictology and Clinical Toxicology and the Center of Alcohol Dependence at UHC "Mother Teresa". All the data were collected from clinical records of patients admitted over this period in these two clinics.

The sample size of this study was 328 patients admitted to these clinics. Almost all of patients were male. The diagnosis of all patients was "alcohol withdrawal syndrome". Patients included in the study were $>22$ years old and underwent treatment in these services for more than 24 hours. The category of patients excluded from the study were $<22$ years old, hospitalized for less than 24 hours, or the patients diagnosed with "alcoholic coma" who were initially hospitalized in the Intensive Care Service.

We took a look on several data of these patients and then we compared these data with those of other authors.

The data that we used are:

- General data : Age(of the patient at admission), Sex, place of residence(for at least the past five years)

Correspondence to: Esmeralda Thoma(Hoxha); Lecturer at Faculty of Technical Medical Sciences; Medical University of Tirana. Rruga e "Dibrës" Nr. 371, AL1005 - Tirane, Tel: 00355699767811; E-mail: esmeraldahoxha@yahoo.com

Key words: alcohol abuse, social aspects, economic aspects

Received: October 11, 2016; Accepted: October 25, 2016; Published: October 28,2016 
- Employment status (Employed, Unemployed, Disabled, Students, pensioners)

- $\quad$ Civil status (Single, Married, Divorced, Widowed)

- Type of alcoholic drink

- $\quad$ Education( Elementary, High school, College degree, Other)

- Time of abusive consumption of alcohol (is categorized $<10$ years and $>10$ years)

- $\quad$ Age of onset of alcohol abuse

All the data are analyzed with SPSS 20.0 program.

\section{Results}

This study included 328 patients, whose mean age was $42.9 \pm 10.8$ years old. The youngest was 22 years old and the oldest was 81 , median results 42 (Table 1 ).

As it is shown in Graph 1 age is presented in the category of 10 years. A total of 39 patients or $11.9 \%$ of the cases were $\leq 30$ years old, a total of 110 cases or $33.5 \%$ of them were $31-40$ years old, 93 cases or $28.4 \%$ of them were $41-50$ years old, a total of 64 cases or $19.5 \%$ of them were $51-60$ years old, 22 patients or $6.7 \%$ of them were $\geq 61$ years old. The results show predominance of the cases in age groups 31-40 years and 41-50 years old, with a statistically significant difference with other age groups $\left(\chi^{2}\right.$ Goodness of fit $\left.=81.2 p<0: 01\right)$. Age is not subject of normal distribution $\mathrm{KS}=0.009$.

\section{Sex of patients}

Almost all of patients in this study were male: $98 \%$ vs $2 \%$. As it is seen, the difference is statistically significant $\mathrm{p}<0.01$.

\section{Geographical distribution of patients' residence}

As we can notice from the Graph 2, the majority of the patients (39 patients or 33.2\%) are from Tirana, which is the capital city of Albania with statistically significant difference from other cities. From Korca city are 20 patients (6.1\%), Elbasan city $16(4 . \%)$ etc.

Table 1. Statistical summary of patients' age.

\begin{tabular}{|c|c|}
\hline Size of sample & $\mathbf{3 2 8}$ \\
\hline The youngest age & 22.0 \\
\hline The oldest age & 81.0 \\
\hline Average & 42.9 \\
\hline Median & 42 \\
\hline Variance & 117.7 \\
\hline Standard Deviation & 10.8 \\
\hline
\end{tabular}

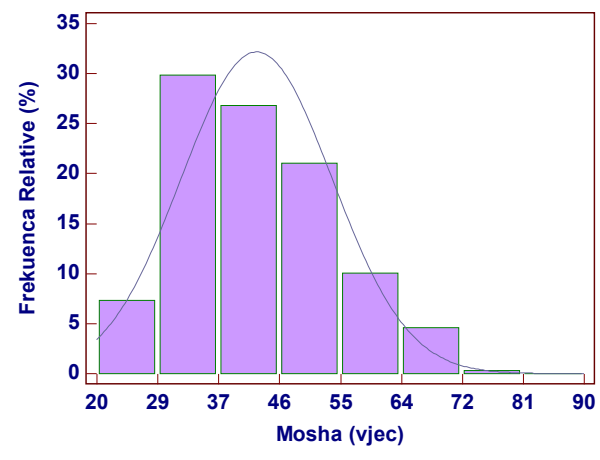

Graph 1. Histogram of patient's age.

\section{Employment status of these patients}

As of the employment status shown here, a considerable number of patients in the study were unemployed -157 patients or $47.9 \%, 144$ or $43.9 \%$ were employed, 15 or $4.6 \%$ of the cases were pensioners, 8 or $2.4 \%$ of cases were disabled and 4 or $1.2 \%$ of the cases were students. The difference is statistically significant $\left(\chi^{2}\right.$ Goodness of fit $\left.=368 p<0: 01\right)$ (Graph 3).

\section{Civil status}

203 or $61.9 \%$ of patients were married, $83(25.3 \%)$ were single, $11.0 \%$ divorced, and $0.6 \%$ were widow. The difference is statistically significant $\left(\chi_{\text {goodness of fit }}^{2}=425.2 \mathrm{p}<0.01\right)$.

\section{Type of alcoholic drink}

The most common type of drink that patients used to drink was raki, which is a traditionally kind of strong alcoholic beverage in Albania. $79.3 \%$ of all patients used to drink raki and $19.5 \%$ used to drink beer. The difference is statistically significant $\left(\left(\chi_{\text {goodness of fit }}^{2}=327.9\right.\right.$ $\mathrm{p}<0.01)($ Graph 4).

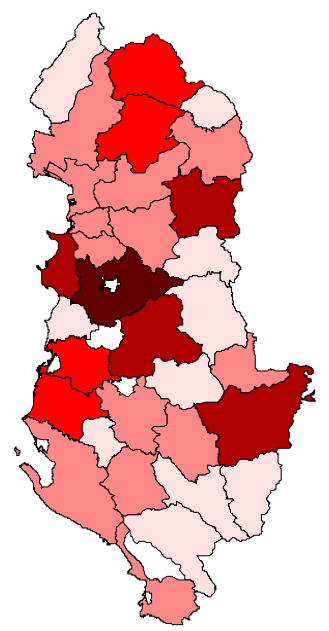

Graph 2. Geographic distribution of patients as of residence.

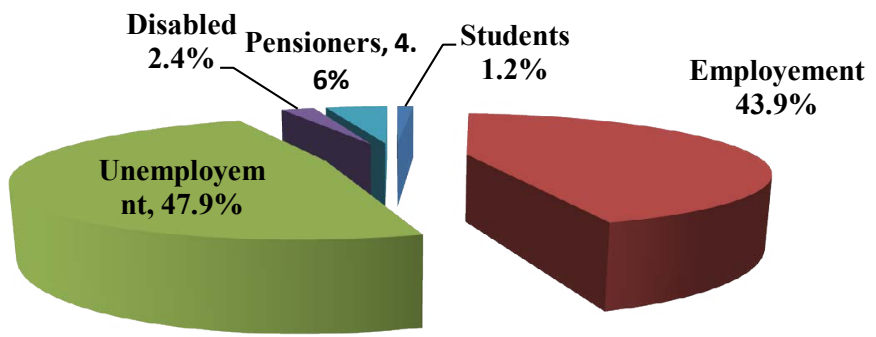

Graph 3. Patients distribution as of employment status.

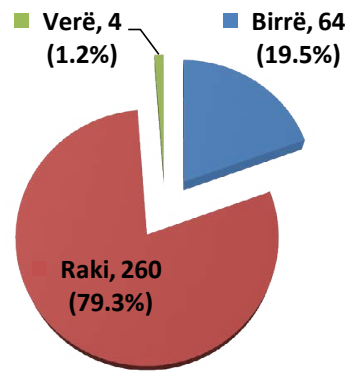

Graph 4. Type of alcoholic drink. 


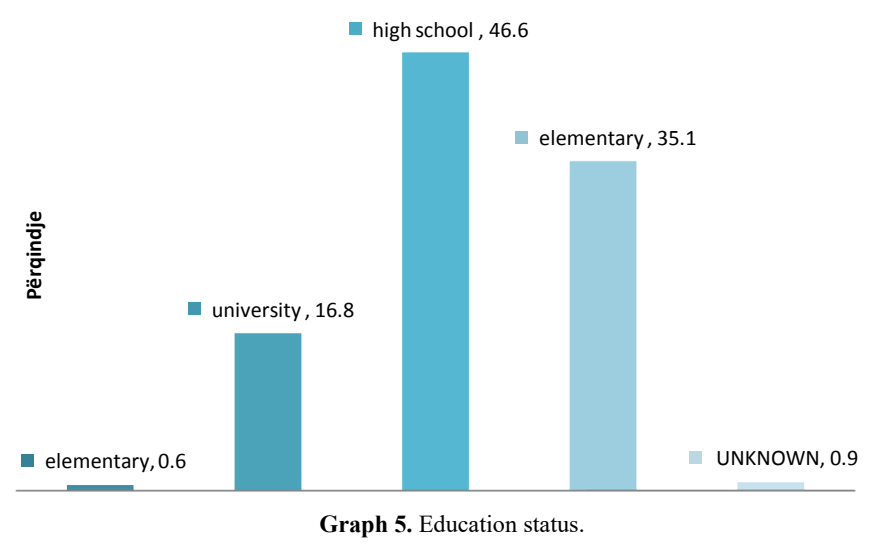

\section{Education status}

Among all the patients of this study, 115 or $35.1 \%$ have elementary education, 153 or $16.8 \%$ of them have a high school graduation and $16.8 \%$ have a university degree. The difference between patients with a high school graduation is statistically significant $\left(\chi_{\text {goodness of fit }}^{2}=276.6\right.$ $\mathrm{p}<0.01)$ as it is seen in the graph 5 .

\section{Age of onset of alcohol abuse}

The mean age of onset of alcohol abuse is $27.9 \pm 7.2$ years old. The youngest was 13 years old and the oldest was 55 years old, median was 29 years old. Patients that started to abuse with alcoholic beverages among $21-30$ years old were $58.5 \%$. The difference is statistically significant among categories of age. $(\chi 2$ goodness of fit $=359.0 \quad p<0.01)$

\section{Discussion}

This study observed and highlighted some aspects of alcohol abuse patients in Albania. Some of the findings in this study are similar to those of other authors, but in our conclusions that our study yielded some exceptional findings. The findings as follows:

For example, in this study, the dominant age group is 31-40 years old (33.55), followed by the age group 41-50 years old (28.4\%). In other studies, it appears that as the age is increasing, the prevalence of alcohol abuse is decreasing $[5,6]$.

Almost all patients of this study are male (98\%). This is mainly because the problem of alcohol abuse in our country is apparently a male phenomenon, or because women do not require medical assistance perhaps due to a great stigma that exists in Albania. As a matter of fact, alcohol consumption is a male habit inherited from the past history of our country, whereas women are stigmatized more, even on behalf of the medical staff women abusers are considered as "bad girls", who will be loved or married by nobody. This is the main reason why we actually do not have, or we have a few reported female abusers.

The majority of patients in this study live in Tirana (33.2\%). We didn't calculate if this is due to the biggest population that lives here compared to other cities, or because in Tirana live the majority of alcohol abusers. However these data are similar to those of other authors. Living in big cities is related with the increase incidence of alcohol abuse and alcohol dependence [7,8].

As for the employment status, in this study we concluded that the majority of alcohol abusers (47.9\%) were unemployed. Why does this happen? First of all, we may say that this is due to the fact that the level of unemployment here in Albania is high [9]. We can easily link this finding with the fact that the most popular drinks that most of the abusers consume, raki, is much cheaper than other alcoholic beverages. Just to compare: one standard raki drink costs about 50 leks (35 cent), one standard beer $330 \mathrm{ml}$ costs about 100-300 leks (1-2.5 euro), not to mention that wine costs a lot more. So, unemployed people find themselves sitting for hours in coffee shops drinking and wasting time with alcohol until they become abusers, or much more dependent. A low number of patients in this study refer that they lost they job as a result of spending time with alcohol, or because of drinking.

They are too many studies that suggest the correlation between unemployment and bad habits of alcohol consumption [9-12].

There are too many studies that highlight the role of marriage in drinking behavior. All of these studies link the marital status with the decreasing rate of alcohol consumption and there is a high number of consumers that abstain for years; on the other hand getting divorced is linked with an increasing rate of alcohol abuse [13-16] (Table 3).

The marital status in Albania doesn't seem to influence alcohol consumption in the same way it does in other countries. $61.9 \%$ of the patients in this study were alcohol abusers, which means that in Albania being married has a negative effect on the level of alcohol consumption. The other reason is that the rate of divorce in Albania is relatively low compared to other western countries. According to one report of INSTAT, the rate of divorce in Albania is increasing, but is still very low, approximately $17.8 \%$ [17].

Meanwhile, the type of alcoholic drink that is mostly consumed differs from country to country. According to the WHO report of 2014, in Albania the most commonly alcoholic drink that is consumed and therefore abused is raki, as is wine in France, beer in Germany, whereas in Great Britain beer, wine and strong drinks are equally consumed [18].

The reason why raki is commonly an abused alcoholic drink is due to the fact that as we mentioned above it is much cheaper than other drinks and because it is manufactured in artisanal conditions by many people.

As other studies highlighted the correlation between the educational level and alcohol abuse, even in this study we took into account this correlation. But, differently from other western countries, where the lower the educational level is, the higher is the probability to abuse with alcohol [19-21], in our country most abusers had high school education $46.6 \%$, followed by elementary school $35.1 \%$. So, the result in Albania is almost the same as in other studies.

The mean age of onset of alcohol abuse is 27.9 years old. We

Table 2. Age of onset of alcohol abuse.

\begin{tabular}{|l|c|c|}
\hline Age of onset & N & \% \\
\hline $\mathbf{2 0}$ years old & 34 & 10.4 \\
\hline $\mathbf{2 1 - 3 0}$ years old & 192 & 58.5 \\
\hline $\mathbf{3 1 - 4 0}$ years old & 82 & 25.0 \\
\hline $\mathbf{4 1 - 5 0}$ years old & 18 & 5.5 \\
\hline $\mathbf{2 0}$ years old & 2 & 0.6 \\
\hline Total & $\mathbf{3 2 8}$ & $\mathbf{1 0 0}$ \\
\hline
\end{tabular}

Table 3. Alcohol consumption and age.

\begin{tabular}{|l|l|l|}
\hline Author & Age and sex & State \\
\hline Bogart et al., 2005 [14] & 1,138 female aged 18-29. & California and Oregon SHBA \\
\hline Dar 2006[15] & Unknown & England \\
\hline Zins et al. $2003[13]$ & 4782 female & France \\
\hline
\end{tabular}


couldn't compare this finding with that of other countries, because other studies are mainly focused on the time of first alcoholic drink consumed. But, this finding is almost similar to that conducted by UNICEF and UNFPA in Albania during 2008-2009 [22].

\section{Conclusions}

There are many aspects of socio-economic life of alcohol abusers that we could highlight. By taking them into consideration, we can interfere in different levels, to reduce abusive alcohol consumption. We highly recommend Albania needs increased awareness about education and health promotion in high schools, talking to students about the short and long term effects of alcohol. Another recommendation is that the process of manufacturing alcoholic drinks in artisanal conditions should absolutely be abandoned, because no one knows how these drinks are manufactured and in what amount. Therefore, we couldn't calculate the exact number of alcoholic beverages sold and drink as there are no statistical data for this.

\section{References}

1. The Social Issues Research Centre; Social and Cultural Aspects of Drinking; A report to the European Commission: March 1998; http://www.sirc.org/publik/drinking biblio.html

2. Besheer J, Grondin JJM, Salling MC, Spanos M, Stevenson RA, et al. (2009) Interoceptive effects of alcohol require mGlu5 receptor activity in the nucleus accumbens. J Neurosci 29: 9582-9591. [Crossref]

3. World Health Organization. Global status report on alcohol. Geneva: World Health Organization; 2004.

4. George Moussas, Christodoulou C, Douzenis A (2009) A short review on aetiology and pathophysiology of alcoholism. Ann Gen Psychiatry 8: 10.

5. Substance Abuse and Mental Health Services Administration, Office of Applied Studies. Results from the 2007 National Survey on Drug Use and Health: National Findings. Rockville, MD: 2008. (NSDUH Series H-34, DHHS Publication No. SMA 08-4343)

6. Schulte MT, Ramo D, Brown SA (2009) Gender Differences in Factors Influencing Alcohol Use and Drinking Progression Among Adolescents. Clin Psychol Rev 29: 535547. [Crossref]

7. Nelson DE, Naimi TS, Brewer RD, Bolen J, Wells HE. (2004) Metropolitan-Area Estimates of Binge Drinking in the United States. Am J Public Health 94: 1295. [Crossref]
8. Rice N, Carr-Hill R, Dixon P, Sutton M (1998) The influence of households on drinking behavior: A multilevel analysis. Soc Sci Med 46: 971-979. [Crossref]

9. Terza JV (2001) “Alcohol Abuse and Employment: A Second Look”. J Appl Econometr forthcoming 17: 393-404

10. Rodriguez E, Lasch KE, Lee J (2001) The relation of family violence, employment status, welfare benefits, and alcohol drinking in the United States. Western J Med 174: 317-323.

11. Edvard J, Hannu A, Urpo K, Kari P (2007) The association of alcohol dependency with employment probability: Evidence from the population survey 'Health 2000 in Finland.' Health Economics 16: 739-754.

12. Popovici I, French MT (2013) Does Unemployment Lead to Greater Alcohol Consumption? Ind Relat (Berkeley) 52: 444-466. [Crossref]

13. Zins M, Gueguen A, Leclerc A, Goldberg M (2003) Alcohol Consumption and Marita Status of French Women in the GAZEL Cohort: A Longitudinal Analysis between 1992 and 1996. Journal of Studies on Alcohol and Drugs 64.

14. Bogart LM, Collins RL, Ellickson PL, Martino SC, Klein DJ (2005) Effects of Early and Later Marriage on Women's Alcohol Use in Young Adulthood: A Prospective Analysis. J Stud Alcohol 66: 6. [Crossref]

15. Dar K (2006) Alcohol use disorders in elderly people: fact or fiction? Advances in Psychiatric Treatment 12: 173-181.

16. Prescott CA, Kendler KS (2001) Associations between marital status and alcohol consumption in a longitudinal study of female twins. J Stud Alcohol 62: 589-604. [Crossref]

17. Filipi Gjergj, INSTAT. Shqiperia ne shifra. www.instat.gov.al/media/294266 shqiperia_ne_shifra_2014.pdf

18. Hasin DS, Stinson SF, Ogburn E, Bridget F (2007) Prevalence, Correlates, Disability, and Comorbidity of DSM-IV Alcohol Abuse and Dependence in the United States Results From the National Epidemiologic Survey on Alcohol and Related Conditions. Arch Gen Psychiatry. 64: 830-842. [Crossref]

19. Crum RM, Anthony JC (2000) Educational level and risk for alcohol abuse and dependence: differences by race-ethnicity. Ethn Dis 10: 39-52. [Crossref]

20. Gilman SE, Breslau J, Conron KJ, Koenen KC, Subramanian SV, et al. (2008) Education and race-ethnicity differences in the lifetime risk of alcohol dependence. $J$ Epidemiol Community Health 62: 224-230. [Crossref]

21. Demographic and Health Survey 2008-09; Institute of Statistics, Institute of Public Health [Albania] and ICF Macro. 2010. Albania Demographic and Health Survey 200809. Tirana, Albania: Institute of Statistics, Institute of Public Health and ICF Macro.

22. Seitz HK, Gärtner U, Egerer G, Simanowski UA (1994) Ethanol metabolism in the gastrointestinal tract and its possible consequences. Alcohol Alcohol Suppl 2: 157-62.

Copyright: (C2016 Thoma(Hoxha) E. This is an open-access article distributed under the terms of the Creative Commons Attribution License, which permits unrestricted use, distribution, and reproduction in any medium, provided the original author and source are credited. 